\title{
Colonialismo y alteridad: el debate racial y cultural en la conquista de Argelia
}

\section{Colonialism and Otherness: The Racial/Cultural Debate During the Conquest of Algeria}

\author{
María Luisa Sánchez-Mejía ${ }^{1}$ \\ Universidad Complutense Madrid (España)
}

Recibido: 29-04-16

Aprobado: 20-06-16

\section{Resumen}

Entre 1830 y 1847 el proyecto para instalar en Argelia una colonia de población europea tuvo que afrontar la realidad de los pueblos que habitaban el territorio. Más allá de la violenta conquista militar, filósofos, políticos y científicos sociales, intentaron analizar las costumbres y la cultura de árabes y bereberes y su futuro en la Argelia francesa. Entre todas las voces destacaron las de Alexis de Tocqueville, que visitó Argelia en 1841 y 1846 para apoyar el proyecto, Amédée Desjobert, diputado republicano, muy crítico con las ideas expansionistas francesas, e Ismayl Urbain, filósofo sansimoniano, partidario de la expansión del Islam por el continente africano. La raza, la religión y el estado de civilización fueron los ejes centrales de un debate que muestra las contradicciones y las fisuras de la política y de la sociedad francesas ante la cuestión colonial.

Palabras-clave: Colonialismo, civilización, alteridad, raza, religión, Tocqueville, sansimonianos.

\footnotetext{
${ }^{1}$ (sanchezmejia@cps.ucm.es) Catedrática de Historia del Pensamiento y de los Movimientos Sociales y Políticos en la Universidad Complutense de Madrid, donde imparte su docencia desde 1983. Especialista en el liberalismo europeo de la primera mitad del siglo XIX, ha dedicado sus tareas de investigación a las alternativas políticas que surgen tras la Revolución francesa, a la relación entre liberalismo y romanticismo, y a los fundamentos teóricos del imperialismo europeo en sus primeras formulaciones. Entre sus publicaciones destacan: Benjamin Constant y la construcción del liberalismo posrevolucionario (1992); "Desencanto político y nostalgia del paraíso en los orígenes del 'mal du siècle"” (1996); "Tradición histórica e innovación política en el primer liberalismo español" (1997); "Repúblicas monárquicas y monarquías republicanas. La reflexión de Sieyès, Necker y Constant sobre las formas de gobierno" (2003); "La teoría política de los Ideólogos" (2004); "Europa ante el espejo asiático: el debate sobre el despotismo oriental en el siglo XVIII" (2008); "Los intereses de Francia: Tocqueville y la cuestión colonial" (2009), "Barbarie y civilización en el discurso nacionalista de la Guerra de África" (2013), "La transformación de la herencia ilustrada: los argumentos del colonialismo en el siglo XIX" (2015). En la actualidad dirige el Grupo de Investigación Política y sociedad en la Europa del siglo XIX, y es Coordinadora del Máster Liderazgo democrático y comunicación política, que imparte la Universidad Complutense.
} 


\begin{abstract}
In 1830-1847, a French project for the colonization of Algiers met with difficulties as the government was forced to deal with the natives. At that time, a number of philosophers, politicians and social scientists began to study the culture and customs of Arabs and Berbers to determine whether locals could play a role in a French-controlled territory. Three such intellectuals became particularly noteworthy: Alexis de Tocqueville, who visited Algiers twice $(1841,1846)$ in order to show his support for the project; Amédée Desjobert, a member of parliament negatively disposed toward French expansionism, and Ismayl Urbain, a Saint-simonian philosopher who supported the spread of Islam throughout Africa. Their discussions centered on issues of race, religion and civilization, while laying out contradictions and conflicts inherent in French politics and society even as the nation prepared to become a modern colonial power.
\end{abstract}

Key-words: Colonialism, civilization, otherness, race, religion, de Tocqueville, Saint-Simonians.

La conquista y colonización de Argelia por parte de Francia no tuvo, en sus primeros años, un proyecto claro y decidido. Iniciada en 1830 con el envío de una expedición de castigo para vindicar el honor de Francia, el último gobierno de la Restauración nunca pretendió convertir el territorio ocupado militarmente en una posesión permanente ni desde luego en una colonia de población, aunque no lo abandonó. La Monarquía de Julio siguió en la misma indecisión mientras se iniciaba la compra de tierras por franceses ávidos de convertirse en colonos y encontrar una vida mejor. En 1834, ante los hechos consumados y la incertidumbre y arbitrariedad que regían el funcionamiento del territorio, se creó un gobierno para las Possesions françaises dans le nord de l'Afrique, Se promulgaron ordenanzas para que fueran sus nuevas leyes y se nombró a un Gobernador general, dependiente del Ministerio de la Guerra, y un consejo de altos funcionarios civiles y militares como asesores. Este reconocimiento explícito de que Francia se hacía cargo de los enclaves ocupados en la denominada Regencia de Argel, dio paso inmediatamente a una viva polémica sobre la política a seguir en los nuevos territorios.

El núcleo central del debate fue la dicotomía entre la creación de una colonia de población o el mero control de ciertos puntos estratégicos en la región. Políticos, militares, viajeros y publicistas defendieron opiniones en uno y otro sentido, al tiempo que nuevos colonos llegaban a la antigua Regencia. La política de colonización, que parecían aceptar de manera tácita los sucesivos gobiernos de la Monarquía de Julio, implicaba nuevas y más fuertes polémicas 
sobre la extensión de la colonia, el carácter y el gobierno de los colonos y, sobre todo, la guerra permanente que era preciso mantener con la población que habitaba el territorio. De esta última cuestión surgió el problema de qué hacer con los indígenas, qué relaciones establecer con ellos y qué lugar debían ocupar en el diseño final para el conjunto del territorio.

Este fue un problema en cierto modo secundario, colateral diríamos hoy. Las preocupaciones principales que se reflejan en la mayoría de los numerosos textos de la época, son el coste de la guerra, las expectativas de los colonos y la política más adecuada para consolidar la presencia francesa en el norte de África. Los argelinos eran "los enemigos", el obstáculo principal para la construcción de la colonia, aunque la llegada de los sansimonianos y sus utópicos proyectos de futuro, aportaron una visión distinta del eurocentrismo imperante. Pero, a pesar de que nunca ocuparan un lugar central, las consideraciones sobre los pueblos que habitaban la Regencia de Argel antes de la llegada de los franceses reflejan la difícil relación entre determinadas convicciones políticas de igualdad, progreso o democracia y su confrontación con una alteridad cultural que no se sabe cómo abordar y mucho menos como encajar en el plan general del colonialismo europeo.

En este discurso argelino, que se va elaborando entre 1834 y 1847 (fecha de la derrota definitiva de Abd-el Kader²), destacan, por un lado, las opiniones de Alexis de Tocqueville, defensor del establecimiento de una colonia de población, y que visitó Argelia en 1841y 1846, como miembro de una Comisión de diputados de la Asamblea francesa ${ }^{3}$, y, como contrapunto

\footnotetext{
2 Abd-el-Kader (1808-1883) fue el líder de la resistencia argelina, admirado y odiado por los franceses. Con solo veinticuatro años tomó el título religioso de emir y logró unir a las tribus y dotar al conjunto de cierta organización administrativa y militar. Derrotado en la batalla de Isly, fue hecho prisionero e internado en Francia, hasta que obtuvo la libertad con honores en 1852.

3 Tocqueville publicó en 1837 "Deux lettres sur l'Algérie", que aparecieron sin firma en el periódico La Presse de Seine-et-Oise; en 1841 redactó un Travail sur l'Algérie, un borrador o unas reflexiones poco elaboradas, que no llegó a publicarse; y en 1847 presentó ante la Cámara un Rapport sur le projet de loi relatif aux crédits extraordinaires demandés pour l'Algérie, como ponente de la Comisión encabezada por Dufaure. Todos estos textos están publicados en las Oeuvres complètes del autor, volumen III, tomo 1, titulado Écrits et discours politiques, editado por André Jardin, Paris, Gallimard, 1962. Todas las citas de Tocqueville se refieren a esta edición. La bibliografía sobre Tocqueville y Argelia no es muy abundante, pero cabe destacar los siguientes títulos: Mary Lawlor, Alexis de Tocqueville in the Chamber of Deputies. His Views on Foreign and Colonial Policy, Washington D.C., The Catholic University of America Press, 1959; Melvin Richter, Tocqueville on Algeria, "The Review of Politics", vol. 25, 3, pp. 362-398; Tzvetan Todorov, Présentation de De la colonie en Algerie, Paris, Éditions Complexe, 1988; Jennifer Pitts, Empire and Democracy: Tocqueville and the Algeria Question, "The Journal of Political Philosophy", vol. 8, 3 (2000), pp. 295-318; A Turn to Empire. The rise of Imperial Liberalism in Britain and France, Princeton University Press, 2005, cap. 7; Christian Béguin, Tocqueville et l'Algérie, "The Tocqueville Review/La Revue Tocqueville", 2 (2009); Cheryl B. Welch, Out of Africa: Tocqueville's Imperial Voyages, "Review of Middle East Studies", vol. 45, 1 (2011); Françoise Mélonio, Le choc des civilisations: Chassériau et Tocqueville en Algérie [en Chassériau (1819-1856). Un autre romantisme. Actes du colloque organisé para le Musée du Louvre le 16 mars 2002, Paris, La Documentation Française-Musée du Louvre, 2002].
} 
a sus ideas, Amédée Desjobert, igualmente diputado en la Asamblea, republicano moderado, y partidario de un control restringido del territorio ${ }^{4}$. Y, por otro lado, las propuestas de ingeniería social de los sansimonianos, cuyo guía espiritual, Enfantin, llegó a Argelia en 1839, al frente de un nutrido y variado grupo de discípulos, civiles y militares, al servicio de Francia, y uno de cuyos seguidores, Ismayl Urbain, ofreció las ideas más originales. A estas tres reflexiones está dedicado este artículo, aunque no fueron las únicas. Muchas otras voces aportaron también su visión de los pueblos indígenas de la Regencia, como las de Jean-Jacques Baude, diputado nacional, Comisario del rey en Argelia, y autor de un amplio estudio sobre la región ${ }^{5}$; Pellissier de Raynaud, sansimoniano avant la lettre, militar, Director de Asuntos Árabes y uno de los primeros en proponer la fusión entre los dos pueblos ${ }^{6}$; Edouard Lapène, comandante en Bujía y pionero de la etnología ${ }^{7}$; el historiador Honoré Fisquet $^{8}$; Eugène Bodichon, médico civil en Argel $^{9}$, o Dureau de la Malle, historiador y geógrafo ${ }^{10}$.

En todos estos textos, las consideraciones sobre los habitantes autóctonos de la colonia se pueden agrupar en torno a tres conceptos principales: la raza, el carácter y la cultura, y con ellos se va componiendo la imagen que los franceses se hacen de los pueblos argelinos.

La raza como criterio de clasificación y comprensión de las comunidades humanas está en boga en las décadas centrales del siglo XIX. Aunque su uso se había generalizado ya en el XVIII como alternativa científica a las explicaciones biblícas ${ }^{11}$. La creación de las primeras sociedades

\footnotetext{
${ }^{4}$ Amédée Desjobert (1796-1853). Publicó varios análisis sobre el problema de Argelia en la época de la conquista: La question d'Alger, Politique, Colonization, Commerce, Paris, Capelet, 1837; L'Algérie en 1838, Paris, Dufart, 1838; L'Algérie en 1844, Paris, Guillaumin, 1844; y L'Algerie en 1846, Paris, Guillaumin, 1846.

5 Jean Jacques Baude (1792-1862), L'Algérie, Bruxelles et Leipzig, Meline, Cans et Compagnie, 1841,2 vols.

${ }^{6}$ Edmond Pellissier de Reynaud (1798-1858), Les Annales Algériens, Paris, Anselin et Gaultier -Laguionie, 1836-1854, 3 vols. En el último volumen, el autor cambió de opinión sobre la necesidad de fusionar a los pueblos árabe y francés.

${ }^{7}$ Edouard Lapène (1790-1854), Les Kabaïles comparés aux Numides et aux Vandales, Paris, Anselin et Gaultier-Laguionie, s.f.

${ }^{8}$ Honoré Fisquet (1818-1883), Histoire de l'Algérie depuis les temps anciens jusqu'à nos jours: publié d'après les écrits et les documents les plus officiels, Paris, Baudouin, 1842.

${ }^{9}$ Eugène Bodichon (1810-1885), Considération sur l'Algérie, Paris, Comptoir Central de la Libraire, 1845.

${ }^{10}$ Adolphe Dureau de la Malle (1777-1857), Recherches sur l'histoire de la régence d'Alger et sur la colonisation de l'Afrique sous la domination romaine, Paris, 1837.

${ }^{11}$ La primera clasificación racial data de finales del siglo XVII y la realiza François Bernier (vid. Sierp Stuurman, François Bernier and the Invention of Racial Classification, "History Workshop Journal", Autumn (2000), pp. 1-21). El siglo XVIII conoce una amplia polémica entre monogénesis y poligénesis, y la expansión colonial del siglo XIX convierte a la raza en un concepto central de las reflexiones sobre los no europeos (Vid. Edward Beasley, The Victorian Reinvention of Race, New Racism and the Problem of Grouping in the Human Sciences, New York, Routledge, 2010, y Arno Sonderegger: Anglophone discourses on Race in the 19th century:
} 
antropológicas y, sobre todo, el inicio de la expansión colonial europea por África convirtieron el recurso a la raza en insoslayable. La clasificación racial no tiene necesariamente un sesgo racista, en el sentido que hoy damos a ese término, aunque a veces sea así. Su uso tiene más un sentido racialista, término que no encontraremos en el Diccionario de la Real Academia, y que fue una traducción del inglés racialism, ahora también en desuso por su parecido lingüístico con racism. Se trataría de atender a las diferencias entre los seres humanos en función de sus características físicas a fin de comprender mejor tanto su forma de vida como el medio en el que se desenvuelven, pero sin establecer grados o escalas de bondad entre ellas, sin que tenga que haber unas razas naturalmente superiores a otras.

Por eso las consideraciones sobre las razas van con frecuencia acompañadas por reflexiones sobre lo que podríamos llamar, atendiendo al sentido de los textos estudiados, el carácter o la manera de comportarse de los distintos grupos humanos registrados. Aquí el elemento dominante es el binomio razón/pasión, que va en ciertos casos unido a la raza y que se relaciona siempre con el medio natural en que se desarrolla la vida de las comunidades humanas, y especialmente con las características del clima. La insuficiencia de las distinciones raciales lleva a buscar en las maneras de reaccionar ante los desafíos vitales una explicación de las diferencias entre los pueblos. Tan importante parece el estudio del comportamiento que un autor como John Stuart Mill, siempre preocupado por dotar de un método científico al estudio de lo que hoy llamamos las Ciencias Sociales, propone la institución de un campo específico denominado etología para dar cuenta sistemática de la manera de ser de los grupos humanos ${ }^{12}$.

Sin embargo, muchas veces, cuando los europeos se enfrentan a la alteridad argelina, se detienen en todo un conjunto de elementos que incluyen la religión, las costumbres, el régimen de propiedad, las jerarquías sociales y un largo etcétera que marcan la separación entre nosotros y ellos, entre the West and the rest, por utilizar el título de una conocida obra sobre la auto percepción occidental ${ }^{13}$. En este conjunto de notas distintivas, que hoy llamaríamos cultura, es donde aparece la dicotomía civilización/ barbarie, que atraviesa toda la reflexión de los europeos en éstas décadas de expansión colonial.

British and African Perspectives, "Stichproben. Wiener Zeitschrift für kritische Afrikastudien”, 16 (2009), pp. 45-85).

${ }^{12}$ Francisco Álvarez, Mill, la etología que nunca se escribió [en Roberto R. Armayo, Javier Muguerza, Antonio Valdecantos, comps.: El individuo y la historia. Antinomias de la herencia moderna, Barcelona, Paidós, 1995], pp. 79-97.

${ }^{13}$ Niall Ferguson, Civilization: The West and the Rest, London, Penguin Books, Allen Lane, 2011. 


\section{Cabileños y árabes}

Cuando los franceses llegan a Argelia, su bagaje cultural les proporciona un primer plano de situación: es la tierra de los antiguos númidas, sometidos por Cartago y después por Roma, que hizo florecer allí la civilización hasta que desapareció de nuevo a manos de los árabes. Ahora hay que retomar la antorcha que dejaron los romanos y completar y consolidar la tarea. Francia es la heredera manifiesta del Imperio romano, y su misión en el norte de África será una moderna pax romana, en beneficio de todo el Mediterráneo. No faltó tampoco el mito medieval de la cruzada, de la cruz contra la media luna ${ }^{14}$, pero los autores clásicos fueron más leídos que la Jerusalén libertada del Tasso ${ }^{15}$. Salustio y La guerra de Yugurta, Estrabón, Polibio y Tito Livio fueron los más citados, pero sobre todo, la Germania de Tácito, que proporcionó el perfil del bárbaro: amigo de la libertad, fuerte sentido del honor, carácter sagrado de la vida familiar y cierta forma primitiva de igualdad. Niños grandes que precisaban de la tutela romana-ahora francesa- para alcanzar la madurez ${ }^{16}$.

En este recuerdo histórico, la división entre bereberes y árabes encajaba a la perfección. Los primeros eran los habitantes originales del territorio, los descendientes de los númidas, los que ya habían gustado de la civilización romana. Los llamaron kabyles, cabileños, por estar asentados en la región montañosa de la Cabilia, y los franceses siempre pensaron -durante los años de la conquista- que sería más fácil entenderse con ellos que con los árabes. Aun antes de ocupar militarmente la región, se fue divulgando que los cabileños eran sedentarios, agricultores, comerciantes, "construyen casas, y saben explotar minas de hierro... y elaborar burdos tejidos" como dice Tocqueville ${ }^{17}$. Los primeros filólogos que se ocuparon de su lengua vieron en ella una connotación de mayor arraigo en la tierra, en el territorio, una vinculación más nacional, frente a la filiación más tribal de la lengua y del comportamiento árabe. Los franceses se identificaban más con la primera actitud ${ }^{18}$.

Este perfil podría inducir a pensar que los franceses consideraban a los cabileños en un estado de civilización más avanzado que el de los árabes. Sin embargo no era así en general: "Están aún divididos en pequeñas tribus -dice Tocqueville-como en las primera edad del mundo", y su situación es tan cercana al buen salvaje que hubieran hecho las delicias de Rousseau, casi tan libres como

${ }^{14}$ Honoré Fisquet (1818-1883), Histoire de l'Algérie depuis les temps anciens jusqu'à nos jours : publié d'après les écrits et les documents les plus officiels, Paris, Baudouin, 1842, pp. 7-8.

${ }^{15}$ La Jerusalén Libertada fue en cambio la referencia obligada en la denominada Guerra de África, de 1859-60, que llevó a España a la conquista de Tetuán. El carácter religioso que muchos quisieron dar a esta guerra colonial hizo que las referencias a los clásicos estuvieran ausentes.

${ }_{16}$ Patricia M.E. Lorcin, Kabyles, arabes, français: identités coloniales. Presses de l'Université de Limoges, 2005, p. 35 y ss.

17 Tocqueville, Première Lettre sur l'Algérie (23 Juin 1837), op. cit., p. 131.

${ }_{18}$ Lorcin op. cit. p. 66. 
los individuos solitarios que disfrutan de su primitiva independencia; ni ricos ni pobres, ni servidores ni amos, nombran a sus propios jefes y están contentos y acomodados a su suerte ${ }^{19}$. Y Desjobert coincide en este primitivismo esencial: "su amor a la independencia les hace lo bastante sabios para sentir muy pocas necesidades y lo bastante industriosos para satisfacerlas sin ayuda de nadie" 20 . Pero no hay finalmente mucha idealización de ese estado natural, porque "para ellos no hay más ley que la fuerza" ${ }^{21}$, y viven tan aislados que si apareciera un extranjero en su territorio, aunque solo fuera para conversar, sin duda le cortarían la cabeza ${ }^{22}$.

La Cabilia resistió durante más de quince años, y en realidad su conquista requirió más esfuerzo que el dominio de la llanura donde habitaban los árabes, pero estos montañeses, considerados rudos y elementales, conservaron durante mucho tiempo las simpatías de los franceses porque sabían defender con orgullo y tenacidad la tierra que habitaban y cultivaban, y eso les hacía más cercanos a los europeos que el imaginado nomadeo constante de los árabes. Los cabileños vivían además la religión de manera más pragmática, menos fanática que los árabes, en opinión de los franceses. Y no faltó quien asoció sus tatuajes en forma de cruz con el recuerdo del cristianismo que una vez profesaron los númidas antes de la llegada del Islam ${ }^{23}$. Todos estos elementos contribuyeron a la creación del "mito cabileño" que dividió desde el principio a la población argelina en una dualidad maniquea: cabileños, sedentarios, buenos; árabes, nómadas, malos $^{24}$.

La connotación negativa del nomadismo procede fundamentalmente de las dificultades que oponía al control por parte del ejército francés. No servía de nada ocupar un territorio si no implicaba también ocupar pueblos o aldeas y someter a control a sus habitantes. Los árabes siempre retrocedían ante el avance de las tropas; no defendían ni tierra, ni ciudades, ni cultivos; se escapaban, se escurrían en la inmensidad del desierto, para volver en cuanto el ejército se desplazaba a otro lugar. Era evidente que no todos los árabes eran nómadas y que la estampa exótica de camellos y jaimas solo podía encontrarse al sur del territorio, y se reconocía también, como hace Tocqueville, que buena parte de la tierra tenía propietarios y títulos de propiedad redactados ante un funcionario público ${ }^{25}$, pero la imagen de la vida errante, sin domicilio

\footnotetext{
${ }^{19}$ Tocqueville, Première Lettre, op. cit. p. 131.

${ }^{20}$ Desjobert, La question d'Alger. op. cit., p. 19. El autor hace suyas afirmaciones que son en realidad del Rapport sur la colonisation, de Lapinsonnière (página 27 del mismo),

${ }^{21}$ Ibid pp. 18-19.

${ }^{22}$ Tocqueville, Première lettre, p. 132.

${ }^{23}$ Edouard Lapène, Tableau historique de l'Algérie depuis l'occupation Romaine jusqu'à la conquête par les Français en 1830, recogido por Lorcin, op. cit. p. 36. Lapène retoma aquí sin duda el relato que aparece en la Topographía e Historia general de Argel, publicada por Diego de Haedo, en Valladolid en 1612.

${ }^{24}$ Lorcin, op. cit. p. 12 y ss.

25 Tocqueville . Première Lettre, op. cit. pp. 131-32.
} 
fijo y sin ocupaciones cotidianas era predominante: "Distan de haberse hecho enteramente sedentarios: tienen casas unos pocos, los más siguen viviendo en tiendas según su antigua usanza". Cada tribu tiene su territorio, baldío casi siempre o cultivado con poca destreza. Están en situación de transición, entre la vida nómada y la sedentaria. Al sur ya no hay linderos ni mojones ni títulos de propiedad, solo la soledad del desierto ${ }^{26}$. Y completa así el retrato de los árabes: "Dan poco valor a la vida humana, desdeñan el comercio y las artes..., y, así, lo que ellos estiman más es la guerra, la pompa y el ruido"27. Pero lo que más escandaliza a los franceses es su radicalismo religioso. Cada tribu está dirigida por una aristocracia más religiosa que guerrera, como es el caso de Abd-el-Kader, y su fanatismo convierte en guerra santa la resistencia contra los europeos, y les hace impermeables a cualquier cambio, acuerdo o ventaja que los franceses puedan ofrecer.

Cuál es su situación en la escala de la civilización con respecto a los cabileños, o a los antiguos dominadores turcos, es algo poco claro, si juzgamos por las denominaciones que se emplean para describir a unos y a otros. Los textos se refieren a ellos indistintamente como salvajes, semisalvajes, bárbaros, semibárbaros o semicivilizados, en una indecisión que indica una sinonimia común en la época. Si bien los pueblos islámicos y los asiáticos en general eran considerados casi civilizados, en comparación con los amerindios o con los subsaharianos, se englobaban bajo las denominaciones antes mencionadas para marcar la distancia con los europeos. A pesar de los esfuerzos de los primeros orientalistas en ensalzar las culturas de la India cuando empezaron a ser mejor conocidas por los británicos, los publicistas y los teóricos tomaban como indicadores elementos sociales y políticos que demostraban el salvajismo o la barbarie de los no occidentales ${ }^{28}$. No es este el lugar para enumerar estos elementos, sobre los que cada vez hay más investigaciones, pero sí de intentar encontrar en los textos objeto de nuestro análisis el denominador común a bereberes y árabes, que convierten a ambos en bárbaros y/o salvajes, a pesar de sus diferencias en su relación con la tierra, la propiedad, la estructura social o la religión.

Además de ciertos rasgos que se juzgan evidentes y sobre los que no es necesario insistir, como el rechazo de la vida urbana o la simplicidad de una vida con muy pocas necesidades materiales, hay dos elementos que identifican a los no civilizados: el inmovilismo social y cultural y el carácter pasional de su comportamiento.

Las sociedades salvajes o bárbaras son estáticas; las civilizadas son dinámicas, progresan. Esta afirmación constituye el punto de partida de la

\footnotetext{
${ }^{26}$ Tocqueville, Première Lettre, op. cit., pp. 132-133.

27 Ibid, p. 135.

28 Vid. Eric Stokes, The English Utilitarians and India. Oxford, Clarendon Press, 1959.
} 
Histoire générale de la civilisation en Europe de Guizot, publicada en 1828: "La noción de progreso, de desarrollo, me parece la idea fundamental entre las que la palabra 'civilización' contiene". Una sociedad puede estar bien organizada, ser próspera, estar razonablemente bien gobernada, pero si no hay avances, cambios, mejoras, no se puede decir que sea una sociedad civilizada ${ }^{29}$. Árabes y bereberes son pueblos anclados en el pasado, en su tradición y costumbres, como si el tiempo no hubiera transcurrido: "Aún hoy los árabes de la costa africana viven divididos en pequeñas tribus prácticamente independientes entre sí, como vivían hace mil doscientos años en Arabia cuando su gran ardor religioso los empujó, todos a un tiempo, hacia Occidente." ${ }^{30}$, insiste Tocqueville en su primera descripción de Argelia. Para Desjobert el rasgo principal de los árabes es que "Han conservado las costumbres de sus antepasados" ${ }^{31}$; y no falta incluso quien describe ritos ancestrales procedentes del interior de África que evidencian la persistencia en algunos grupos de una primitiva religión fetichista $^{32}$. La división en tribus es la prueba evidente de un anclaje en el pasado remoto de la Humanidad, algo que ni siquiera los turcos lograron deshacer, y que sitúa a cabileños y árabes en un momento anterior incluso al del despotismo oriental practicado por los turcos y tan denostado siempre por los europeos.

Pero no es necesariamente un estancamiento definitivo. Los estímulos exteriores, como la presencia de los franceses, pueden poner en marcha el motor de la evolución. Tocqueville compara a menudo la situación de las tribus árabes con la Edad Media europea, en la que los señores feudales se enseñoreaban de tierra y súbditos y guerreaban con los vecinos. Sin embargo, continúa, Abd-el Kader, para optimizar la guerra contra Francia, está acabando con los todopoderosos jefes de tribu, para unificar fuerzas bajo su mando, como

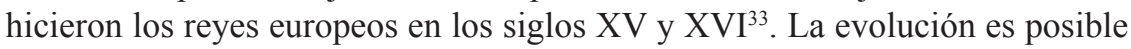
y es quizá el aislamiento el que la ha impedido.

Al igual que las sociedades, los individuos tampoco han evolucionado, no han madurado. Todos los rasgos que definen a los argelinos en los diferentes textos abundan en su incapacidad para el autodominio y en la entrega al capricho inmediato. "Bravos en el combate, son feroces tras la victoria", "abandonados al estado de naturaleza, su carácter rige sus pasiones: sobre todas ellas domina la de vengar las ofensas", asegura Desjobert. Y Tocqueville describe así a los árabes:

\footnotetext{
${ }^{29}$ François Guizot, Cours d'Histoire moderne. Histoire générale de la civilisation en Europe, Bruxelles, Sociéte Belge de Librairie, 1839, pp. 10-11.

${ }^{30}$ Tocqueville, Première Lettre, op. cit., p. 133.

${ }^{31}$ Desjobert, La question d'Alger, op. cit. p. 21.

${ }^{32}$ El baron Baude describe un rito de pacto secreto de mujeres con el demonio para que sus maridos hagan buena presa de cristianos: L'Algérie, op. cit., vol. I, p. 63.

${ }^{33}$ Tocqueville, Travail sur l'Algérie (1841), op. cit. p. 223.
} 


\begin{abstract}
"la imaginación brillante y sensual, el ingenio agudo, sagaz, el coraje y la inconstancia que exhibían sus mayores. Como aquellos, pertenecen a esa raza mudable e indómita que adora los placeres físicos... Desconfiados y crédulos, tan pronto son presa de irreflexivo entusiasmo como de abatimiento exagerado: les cuesta poco caer y levantarse, a menudo excediéndose en sus actos y dispuestos siempre a sentir, antes que a pensar" 34 .
\end{abstract}

Y aun sus señores naturales no pueden gobernarlos en sentido contrario a sus pasiones y han de ceder ante ellas, al carecer de otros apoyos para sostener su poder, mientras que los reyes europeos gobiernan sobre particulares que pueden ser constreñidos por la fuerza social con la que cuenta el príncipe ${ }^{35}$.

Este predominio de los sentimientos sobre la razón condiciona toda la vida bárbara de las tribus argelinas. Los ideales europeos -y por tanto civilizadosde libertad y autonomía individual "solo son aplicables a los seres humanos en la madurez de sus facultades", como dice John Stuart Mill, y no a los menores de edad, ni a "aquellos estados atrasados de la sociedad en los que la misma raza puede ser considerada como en su minoría de edad"36. Porque la civilización para Mill viene marcada por la conquista de la naturaleza, pero no solo sobre la naturaleza física sino también sobre la naturaleza humana, haciendo triunfar la virtud sobre las inclinaciones más primarias ${ }^{37}$.

\title{
¿Fusión o asociación?
}

Aun cuando se trate de enemigos, de bárbaros o de no civilizados, los habitantes de Argelia están ahí y no se les puede ignorar en el proceso de ocupación del norte de África que ha emprendido Francia. La presencia europea en suelo africano lleva a veces a ensoñaciones utópicas:

\footnotetext{
"Nuestra presencia en África va unida, tal como yo la concibo, a consideraciones del más elevado orden que miran al porvenir de los pueblos y a la palingenesia social. Todo anuncia, todo prepara la gran fusión de Oriente con Occidente, y en nuestra presencia veo yo un paso más hacia esa fusión de la cual ha de brotar, como en tiempos de Cristo y de Mahoma, una nueva irradiación de luz y una nueva transformación de la sociedad humana" ${ }^{38}$.
}

\footnotetext{
${ }^{34}$ Tocqueville, Première Lettre, op. cit., p. 135.

35 Tocqueville, Travail, op. cit., pp. 218-19.

${ }^{36}$ John Stuart Mill, Sobre la libertad, traducción española de Pablo de Azcárate. Madrid, Alianza Editorial, 1981, p. 66.

${ }^{37}$ John Stuart Mill, Three Essays on Religion [en J. Robson, ed.: Collected Works, vol. X, Essays on Ethics, Religion and Society, University of Toronto Press, Routledge \& Kegan Paul, 1969], pp. 392-93.

38 Pellissier de Reynaud, Annales Algèriens, op. cit., vol. I, p. VI.
} 
Otros analistas se acogen a la idea de que la mera presencia de la civilización y sus representantes en el territorio será un imán irresistible para la transformación voluntaria de las tribus argelinas. Genty de Bussy creía en la eficacia del ferrocarril: "La vista dejaría cautivados de admiración a los indígenas" 39 , y el Moniteur algèrien proponía la construcción de un teatro: "A la civilización le serviría de poderosa palanca con que adelantar en gran medida el final de la barbarie" ${ }^{40}$. Tan ingenua confianza en la superioridad de las propias costumbres no es solo una ilusión del imperialismo liberal. Diderot, muy crítico con el colonialismo que se practicaba en su época, consideraba sin embargo que una comunidad de civilizados europeos que se estableciera en los confines del Imperio ruso sería suficiente para liberar a sus habitantes de la barbarie: "los habitantes de las aldeas vecinas verán la prosperidad de los colonos, este espectáculo será el auténtico predicador de la libertad que abrazarán por sí mismos insensiblemente y sin esfuerzo. Hay que hacer lo mismo con un pueblo esclavo que con uno salvaje: convertirlo por medio del ejemplo" ${ }^{41}$. El propio Tocqueville se deja envolver hasta cierto punto por esta ilusión: "Por el solo hecho de la superioridad de sus luces, un pueblo poderoso y civilizado como el nuestro ejerce una influencia casi invencible sobre las pequeñas tribus poco menos que salvajes y, para obligarlas a incorporarse a él, basta que pueda entablar con ellas relaciones durables ${ }^{42}$. Y a pesar de su experiencia como observador de las dificultades de integración de las distintas razas en América, tiene un primer momento de esperanza en la fusión de los pueblos argelino y francés ${ }^{43}$. Crítico de las teorías racistas de su antiguo secretario Arthur de Gobineau, Tocqueville no cree que la raza deba marcar el destino de los pueblos ${ }^{44}$. Sin embargo su viaje a Argelia en 1841 le muestra una realidad muy distinta de la que hubiera imaginado y, en sus escritos posteriores, reconoce la necesidad de contemplar dos comunidades separadas y muy distintas que nunca se fundirán . A partir de ese momento se ocupa fundamentalmente de la construcción y administración de la colonia francesa, y prescinde de los argelinos al menos hasta que el control militar sobre todo el territorio sea efectivo y la colonia pueda funcionar con normalidad. Es el dominio de la región lo que le importa, no el destino de sus habitantes, si bien, una vez cometida la gran violencia de la conquista, siempre conviene ser comedidos: "Por el propio interés de nuestro asentamiento es importantísimo que, a

\footnotetext{
39 Pierre Genty de Bussy, De l'etablissement des français dans la Regence d'Alger, et des moyens d'en assurer la prosperité, 1835, vol. I, p. 298.

40 Desjobert, La question d'Alger, op. cit. p. 302.

${ }^{41}$ E. Adamovsky, Diderot en Rusia, Rusia en Diderot, "Studia Historica", 22 (2000), pp. 245-282.

42 Tocqueville, Seconde Lettre sur l'Algérie, op. cit. p. 148.

${ }^{43}$ Ibid. p. 151.

44 Vid. Fotini Assimacopoulou, Arthur de Gobineau commenté par Alexis de Tocqueville, "The Tocqueville Revue/La Révue Tocqueville”, Vol. XXII, 2 (2001), pp. 197-219.
} 
ojos de los indígenas, procedamos con el derecho de nuestra parte; $\mathrm{y}$, donde el derecho falte, al menos con humanidad y con cierto miramiento"45.

En el extremo casi opuesto está Desjobert. Su continua oposición a la creación de una colonia en el norte de África le lleva a denunciar indeseables intenciones de exterminio de la población argelina por parte de las autoridades francesas: "Al apoderarse de un país para implantar en él una población europea, lo único razonable sería la destrucción de la población indígena. Se mire como se mire y se vista como se vista, este hecho supone siempre la exterminación" ${ }^{\text {"46. }}$.

En cualquier caso, y aun sin llegar al exterminio total de los indígenas, el mantenimiento de la colonia implica una guerra continua y sus consecuencias: grandes pérdidas económicas y de vidas humanas. Desjobert no desea ni la fusión ni la integración de los pueblos argelinos; ni siquiera la creación de una colonia. El control del Mediterráneo puede hacerse ocupando solo dos o tres puertos estratégicos, algo militarmente factible y económicamente soportable. Los intereses geopolíticos de Francia quedarían a salvo, pero también sus intereses morales: los franceses no son buenos colonos; su gobierno basado en la soberanía de la nación y en el sistema representativo se aviene mal con una guerra sin fin y una política colonial que coloca la razón de estado por encima de la discusión abierta en la Cámara ${ }^{47}$. La solución es lo que él denomina el sistema árabe: dejar que los argelinos se gobiernen a sí mismos y ayudar a su evolución enviando a Francia a los hijos de sus dirigentes, como Abd-elKader, para que la educación europea los devuelva a África como civilizados y formen una élite que lleve a sus comunidades a la transformación de leyes y costumbres: "Estos jóvenes, a su regreso a la patria, llevarían consigo algunas ideas nuevas; las naciones solamente pueden progresar desde arriba, no a partir de las clases inferiores"48.

Pero tanto defensores como detractores del establecimiento colonial requieren a Francia para que no traspase los límites que sus costumbres, sus principios y su civilización, en definitiva, les impone. Aunque no se logre persuadir con el ejemplo, como quería Genty de Bussy, es importante que no se disuada por el ejemplo, que los franceses no adopten una "geographical morality", como la llamaba Edmund Burke, que lleva a los europeos a comportarse como bárbaros en cuanto traspasan las fronteras de su continente ${ }^{49}$.

La Francia civilizada "no puede seguir haciendo eso en África", grita Desjobert. El sistema de refoulement (represión) -denuncia- es una expresión que oculta proyectos de exterminio. Se invoca en su apoyo el pasado de América

${ }^{45}$ Carta a Lamoricière de 5 de abril de 1846, recogido en Lucien Jaume, Tocqueville. Les sources aristocratiques de la liberté. Paris, Fayard, 2008, p. 408.

${ }^{46}$ Desjobert, L'Algérie en 1846. op. cit., p. 16.

${ }^{47}$ Desjobert, La question d'Alger, op. cit. pp. 40-41.

${ }^{48}$ Ibid. p. 325.

${ }^{49}$ Edmund Burke, Speech on Opening the Articles of Impeachment, 15 de febrero 1788, [en F. O’Gorman, Edmund Burke. His Political Philosophy, London. Unwin University Books, 1973].

Araucaria. Revista Iberoamericana de Filosofia, Política y Humanidades, año 18, n 36. Segundo semestre de 2016. Pp. 17-39. ISSN 1575-6823 e-ISSN 2340-2199 doi: 10.12795/araucaria.2016.i36.02 
del Norte $^{50}$, pero eso es confundir las diferentes fases de la civilización de los pueblos, al comparar a un pueblo agrícola con un pueblo de cazadores: un pueblo cazador retrocede, un pueblo agrícola $\mathrm{no}^{51}$. Sus defensores, como Genty de Bussy $^{52}$ aseguran que poco se puede hacer con fanáticos e indomables guerreros. Pero este sistema -continúa Desjobert-,

"inadmisible para el estado actual de nuestras sociedades, repugnante a nuestras costumbres y contrario a la fe que hemos jurado, el adoptarlo nos situaría al margen de Europa y levantaría oleadas de indignación contra nosotros. ¡Los actuales franceses bajarían del norte, como antaño los hunos y los vándalos, a masacrar a miles de familias! No, no habría maldiciones bastantes que arrojar sobre nosotros si procedemos de esa suerte" ${ }^{53}$.

Después de su viaje a Argelia, Tocqueville expresaba una queja amarga: "He vuelto de África con la dolorosa idea de que en este momento nosotros hacemos la guerra de un modo harto más bárbaro que los propios árabes. Hoy por hoy la civilización se encuentra de su lado"54. Pensaba que en realidad los franceses habían actuado mal desde el principio: El primer error fue expulsar a todos los turcos cuando los franceses llegaron a Argelia, con lo cual dejaron al territorio sin autoridades ni administradores y destruyeron todos los archivos. Sin documentos no fue posible recaudar el impuesto en sustitución de los turcos. Hubo que pedir dinero a Francia,

\begin{abstract}
“o arrebatárselo a nuestros desdichados súbditos con maneras mucho más turcas que las que han empleado jamás los turcos. Y así, nuestra ignorancia hizo al Gobierno francés opresor y ajeno a las reglas [...] De su antiguo gobierno no dejamos en vigor más que el uso del palo y el yatagán como medios de policía [...] El país... cayó en una anarquía espantosa". Y concluye: "Si lo único que nos proponemos es igualarnos a los turcos, acabaremos quedando en posición bien inferior a la suya: bárbaros por bárbaros, los turcos siempre nos llevarán la ventaja de ser bárbaros musulmanes" ${ }^{55}$.
\end{abstract}

50 Eugène Bodichon, defendía que si los árabes seguían impermeables a toda posibilidad de civilización, había que reservarles la misma suerte que a los indios de América. El establecimiento de una colonia que devolviera la costa de Berbería a la civilización europea exigía que los franceses sobrepasaran los límites de la moral vulgar. Vid. Lorcin, op. cit. p. 59. En realidad Bodichon eran una filántropo, defensor de reformas para la mejora de las clases trabajadoras, pero su filantropía solo se extendía al ámbito de la Francia continental.

51 Desjobert, La question d'Alger, op. cit., p. 91.

${ }^{52}$ Genty de Bussy era partidario decidido de la colonización y de una guerra sin concesiones ni treguas hasta el sometimiento total del territorio. Vid. De l'etablissement des français dans la Regence d'Alger, et des moyens d'en assurer la prosperité, op. cit.

53 Desjobert, La question d'Alger, op. cit. pp. 94-95.

${ }^{54}$ Tocqueville, Travail sur l'Algérie, op. cit. p. 226.

55 Ibid. 
La denuncia de Desjobert o la queja de Tocqueville parecen indicar que la frontera entre civilización y barbarie puede traspasarse fácilmente. Pero hay más de exageración retórica que de autocrítica. Ni el primero cree realmente que los franceses sean como los vándalos ni el segundo que se asemejen a los turcos. Es un recurso para resaltar los errores que se están cometiendo en la política argelina, y defender las alternativas que cada uno propone, porque la distancia entre "ellos" y "nosotros" sigue siendo insalvable.

\title{
El universo sansimoniano
}

La Regencia de Argel ejerció también un enorme atractivo para quienes soñaban con un mundo nuevo. Fue la América de los franceses, un lugar no solo de emigración económica sino un espacio en el que todo estaba por hacer, sin las trabas de la vieja Europa. El propio Tocqueville sacó esa impresión cuando llegó a Argel:

\begin{abstract}
"Primer aspecto de la ciudad: Nunca he visto nada parecido. Una prodigiosa mezcla de razas y vestimentas, árabes, cabileños, moros, negros, mahoneses, franceses. (...) Todas estas gentes se agitan con una actividad que parece febril. Toda la ciudad baja parece en estado de destrucción y de reconstrucción. Solo se ve por todas partes ruinas recientes, edificios que se levantan; solo se oye el ruido del martillo. Es Cincinnati transportado a suelo africano"56.
\end{abstract}

Y nadie con más ensueños que los discípulos de Saint-Simon, liderados por Prosper Enfantin desde 1826, y entregados con un entusiasmo inquebrantable a la causa del progreso y del mundo nuevo.

Los primeros sansimonianos llegaron a Argelia como jefes y oficiales del Ejército de conquista y ocupación del territorio. Salidos casi todos ellos de la célebre École Polythécnique, fundada por Napoleón, asociaban, por tradición y por formación, la tarea militar con el servicio a la sociedad desde diferentes cometidos: la ingeniería, la medicina, la educación y, en general, la reforma social. La adhesión a la doctrina de Saint-Simon les daba fama de republicanos radicales ya en la Escuela, y esa fue una de las razones por las que muchos fueron enviados a Argelia, a combatir al servicio de Francia pero lejos de Francia ${ }^{57}$.

Todos llevaban en su bagaje la lectura de la Description de l'Égypte ${ }^{58}$, las imágenes de la aventura de Napoleón con las pirámides de fondo. Aquel viaje fue el descubrimiento de Oriente por parte de la Europa posrevolucionaria y

\footnotetext{
${ }^{56}$ Tocqueville, Notes du voyage en Algérie de 1841, en Oeuvres Complètes, vol. V, t. II, p. 191.

${ }^{57}$ Lorcin, op. cit., p. 143.

${ }^{58}$ Description de l'Égypte ou Recueil des abservations et des recherches qui ont été faites en Égypte pendant l'expédition de l'Armée française publié par les ordres de sa Majesté l'Empereur Napoléon le Grand, Paris, Imprimerie Impériale, 1809-1822, 9 vols.
} 
su recuerdo presidirá buena parte de la obra de los sansimonianos en Argelia. Las grandiosas ruinas de la espléndida civilización egipcia, y su deterioro en medio de lo que consideraron la indiferencia de la población árabe, impresionó vivamente a los expedicionarios, y se asignaron a sí mismos la misión de recuperar el antiguo lustre de los monumentos de los faraones y enseñar a apreciarlos a los árabes que allí vivían. Esta misión científica y civilizadora se refleja en algunas de las ilustraciones que Denon y otros autores dibujaron para la obra, y la convirtieron en modélica para las futuras aspiraciones expansivas de Francia $^{59}$. Un ferviente republicano, crítico del colonialismo y de la esclavitud, como Jean-Baptiste Say, consideró que Egipto podía ser un ejemplo de una nueva forma de colonización, en la que una minoría - de franceses en este casogobernara a una mayoría de egipcios, librándolos de la administración odiosa y opresiva que sufría el país antes de la llegada de los soldados napoleónicos ${ }^{60}$. $\mathrm{Y}$ aunque los deseos de Say no se realizaran y la estancia de las tropas fuera breve en el tiempo, la memoria de la Descripción de Egipto continuó viva y fue la inspiración constante de la Comission Scientifique, que acometió el estudio geográfico, etnográfico, filológico y cultural del territorio, a partir de 1840, y en la que participaron militares y civiles de la escuela sansimoniana ${ }^{61}$.

El interés científico por la tierra y por los habitantes de la antigua Regencia de Argel no implicaba, desde luego, una mayor apertura de miras a la hora de juzgar una cultura ajena. La dualidad civilización/barbarie pertenece también al lenguaje de los sansimonianos, y con los mismos tonos de tajante evidencia que en los autores socialmente menos radicales, como ya hemos visto. Lamoricière, oficial sansimoniano, que llegó a ser Gobernador General de Argelia y participó en la captura de Abd-el-Kader, consideraba que la guerra era necesaria, e incluso beneficiosa, en los países bárbaros

\footnotetext{
"Es una obra de apostolado para gentes que no escucharían mucho tiempo los razonamientos si no estuvieran apoyados por las bayonetas. Veo la conquista como un medio poderoso de importación de ideas [....] El pueblo árabe tuvo en otro tiempo una misión de proselitismo en Oriente y por todas partes dejó huellas profundas de su paso. Quizá deba reaparecer en escena en un mundo iniciado por nuestras creencias en el porvenir" 62 .
}

${ }^{59}$ Lorcin, op. cit., pp. 144-145, y Osama W. Abi-Mershed, Apostles of Modernity. Saint-Simonians and Civilizing Mission in Argelia, Stanford University Press. 2010.

${ }^{60}$ J.B. De l'Egypt [en A. Plassart, Un 'Impérialiste Libéral': Jean-Baptiste Say on Colonies and the Extra-European World, "French Political Studies", 32, 2 (2009), pp. 246-7.

${ }^{61}$ Los resultados se publicaron a partir de 1844: Exploration scientifique de l'Algérie pendant les années 1840, 1841, 1842, publiée par ordre du gouvernement et avec le concours d'une commission académique, Paris : Impr. royale, 1844-1867, 39 vols.

${ }^{62}$ Recogido por Marcel Emerit, Les saint-simoniens en Algérie”, Paris, Les Belles Lettres, 1941, pp. 59-60.

Araucaria. Revista Iberoamericana de Filosofía, Política y Humanidades, año 18, n ${ }^{\circ} 36$. Segundo semestre de 2016. Pp. 17-39. ISSN 1575-6823 e-ISSN 2340-2199 doi: 10.12795/araucaria.2016.i36.02 
En cierto modo, Lamoricière recoge en esta posibilidad de que la cultura árabe recobre un pasado esplendor bajo el liderazgo francés un eco de la idea de Say de recuperar la cultura egipcia a través de la actuación de los soldados napoleónicos. Los sansimonianos mantuvieron pues, en general, una línea más innovadora en el ámbito técnico y científico que en el social y cultural.

La llegada, en 1838, de Prosper Enfantin, introdujo sin embargo algunas novedades en la visión de conjunto de los sansimonianos franco-argelinos. Con Enfantin, los seguidores de las ideas de Saint-Simon se habían convertido en un grupo al que bien podría calificarse de secta, por su búsqueda de una espiritualidad adaptada al signo de los tiempos, a la vez que mantenía la fraternidad cristiana. La nueva religión intentaba unir, en una síntesis extravagante difícil de apreciar por los gentiles, el progreso científico-técnico, la reforma social y el sentido último del universo, con nuevas y creativas visiones de un futuro mejor.

En este marco político-religioso, se afianza la idea de que el mundo actual está formado por naciones solteras, que se irán uniendo a través de grandes vías de comunicación y grandes alianzas espirituales: "La raza mejor organizada -decía Rouen-, en circunstancias climáticas iguales, se civiliza la primera y detiene el desarrollo de las razas inferiores porque las subyuga (...) y asimila a los animales domésticos hasta que la asociación sea comprendida y admitida" ${ }^{\prime 3}$. Los sansimonianos consideraban su deber reivindicar la tarea de acelerar esta asociación, y mientras Gustave d'Eichthal soñaba con maridar el mundo blanco y el mundo negro, Michel Chevalier lanzaba la idea de una unión entre Oriente y Occidente. Para él, estas dos partes de la humanidad simbolizan el viejo dualismo del cuerpo y del alma. Pero ha llegado el momento en que Dios bendiga la unión. Occidente aportará su técnica y su formación científica. Oriente dará su sentido social, la nobleza de carácter y el espíritu religioso. Será un matrimonio de la materia y el espíritu, de la ciencia y de la industria, de la teoría y la práctica ${ }^{64}$.

Enfantin, que se autodenominaba el Padre de la nueva religión y llevaba escrito su título en su vestimenta, deseaba encontrar a la Madre, la mujer perfecta para amadrinar a la secta. En 1832, a la salida de prisión tras cumplir condena por predicar el amor libre, el Padre y un grupo de seguidores viajaron hasta el Cairo en busca de la dama en cuestión, guiados, ellos también, por el recuerdo de la expedición napoleónica. Aprendieron árabe, algunos desposaron a mujeres egipcias, adoptaron las costumbres del país y trataron de convencer al Pachá de excavar un canal en Suez. El Padre pensaba que no se debía conquistar nada por la violencia ni destronar a ninguna raza:

${ }^{63}$ Ibid., p. 47. Rouen era redactor de Le Producteur, un periódico sansimoniano que se publicó en 1825-26.

64 Ibid.

Araucaria. Revista Iberoamericana de Filosofía, Política y Humanidades, año 18, n 36. Segundo semestre de 2016. Pp. 17-39. ISSN 1575-6823 e-ISSN 2340-2199 doi: 10.12795/araucaria.2016.i36.02 


\begin{abstract}
"Que los musulmanes de Constantinopla continúen estudiando francés, matemáticas, que vayan a nuestros teatros, nuestros placeres bajo sus ojos, que beban vino y no tomen más que a una mujer, y pronto serán nuestros mil veces más que si montamos una guarnición en El Cairo, en Esmirna o en Scutari, y mil veces más nuestros que de los rusos o de los ingleses!" ${ }^{65}$.
\end{abstract}

Se trata de la vieja creencia de que el ejemplo que proporcionen los europeos, con sus costumbres y sus valores, será el mejor instrumento para civilizar culturas ajenas. La convicción de la propia superioridad cultural y moral sigue siendo igual de ingenua entre los apóstoles de la modernidad como lo era en la mente de los ilustrados.

Hacia 1835, la mayoría, en mala situación económica y afectados por el cólera, volvieron a París. Aunque algunos dieron por terminada su aventura y se convirtieron en prósperos hombres de negocios, los más entusiastas descubrieron pronto un nuevo Oriente en Argelia, donde sus correligionarios del Ejército estaban ya instalados ${ }^{66}$.

El propio Enfantin encabezó el grupo, convencido de la necesidad de colonizar Argelia para realizar la gran fusión de las razas y civilizar por el contacto. Los colonos se irán fusionando con los indígenas: una población macho, la europea, y otra hembra, la argelina, irán formando nuevas familias, y fundando nuevos pueblos y ciudades. La misma ilusión de Tocqueville y la misma desilusión: de la fusión Enfantin pasará a un contacto "a distancia" entre franceses y argelinos y a la esperanza de que la convivencia y las mutuas influencias desarrollarán un auténtico espíritu colonial y de él surgirá una nueva civilización ${ }^{67}$.

Algunos elementos de las costumbres árabes pueden facilitar, con el tiempo, el surgimiento de ese mundo nuevo, como la manera de poseer las tierras y la falta de ese egoísmo y esa codicia tan europea sobre los bienes materiales. El juez Marion, un sansimoniano de Bona, publicó un folleto titulado "Lettre sur la constitution de la proprieté chez les arabes". Afirmaba que la propiedad privada, tal como se conoce en Europa, no existía en Argelia, salvo en las ciudades y sus alrededores. Las tribus solo tenían derechos de explotación y administración; ni siquiera se trataba de una propiedad colectiva de una tribu determinada, sino de una especie de usufructo de unos bienes que pertenecían a Dios y que estaba regulado por el Corán. Este descubrimiento permitía considerar casi toda la tierra como "bienes nacionales" y disponer de ellos a conveniencia. Pero Marion no quería que esas tierras se repartieran entre los colonos que llegaban a Argelia; él soñaba con una propiedad colectiva, inteligente y equitativamente

\footnotetext{
${ }^{65}$ Ibid. p. 95.

${ }^{66}$ Pamela M. Pilbeam: The Colonization of Algeria: The role of saint-simonians, http//www.hfrance.net/rude/rudevolvi/PilbeamVo16.pdf, p. 190, consultado el 2 de febrero de 2016.

${ }^{67}$ Marcel Emerit, op. cit. pp. 107 y 122.
} 
comunitaria. Era un magnífico punto de partida para una experiencia socialista, tal como siempre habían predicado los sansimonianos ${ }^{68}$, y Enfantin concibió grandes proyectos mientras se hacía incluir en la gran Comission Scientifique. Sus conclusiones quedaron publicadas en su obra Colonisation de l'Algérie, de 1843 , en la que defendía una colonización por civiles y no por antiguos soldados, como estaba haciendo el gobierno de la colonia, y ofrecía algunas recomendaciones para una organización del trabajo y de la propiedad más cercana al socialismo ${ }^{69}$.

\section{El patriota musulmán}

El último personaje de este relato de encuentros y desencuentros con la población argelina es probablemente el más peculiar. En el grupo de sansimonianos en busca de un nuevo Oriente, llegó a Argel el discípulo más entusiasta de la doctrina y el menos acomodaticio a los proyectos de Enfantin: Thomas Ysmail Urbain. Hijo de un comerciante francés y de una antigua esclava africana, era originario de la Guayana, una de los pocas colonias francesas antes de la conquista de Argelia. Fue uno de los que aprovechó el viaje a Egipto de la secta para aprender árabe, convertirse al Islam y adoptar la vestimenta musulmana. Esta transformación le permitió hacer una larga y provechosa carrera en Argelia, como intérprete primero, como mediador oficial u oficioso entre las autoridades francesas y la sociedad indígena $\mathrm{y}$, finalmente, como funcionario del Ministerio francés de la Guerra, después de haber recibido, en 1844, la Legión de Honor.

En 1839 publicó, junto a Gustave d'Eichthal, unas Lettres sur la race noire et la race blanche $e^{70}$, que reflejan a la vez el espíritu científico-espiritual de los sansimonianos y la postura que defenderá Urbain, a veces incluso contra las ideas del mismísimo Padre. El breve folleto, de apenas 70 páginas, recoge el intercambio de cartas entre los dos amigos, interesados en otorgar a la raza un papel preponderante en la nueva organización de la gran familia humana. D' Eichthal y Urbain creen que hasta ahora los filósofos se han centrado en el análisis del individuo, pero que, de acuerdo con la nueva filosofía positiva, es preciso considerar más bien a la familia, y averiguar, como hacen los zoólogos -a quienes va dedicada la obra- el sexo y la filiación dentro de la gran familia humana, explicar quién es el macho y quién la hembra, quienes pertenecen a la generación anterior y quienes a la generación nueva.

\footnotetext{
${ }^{68}$ Ibid. p. 101.

${ }^{69}$ Prosper Enfantin, Colonisation de l'Algérie, Paris, Bertrand, 1843. Pilbeam, op.cit., p. 192.

${ }^{70}$ Gustave d'Eichthal e Ismayl Urbain, Lettres sur la race noire et la race blanche, Paris, Chez Paulin éditeur, 1839.
} 
En su opinión el camino para la reconciliación entre las razas negra y blanca pasa por el reconocimiento de las grandes diferencias que hay entre ellas, y por aceptar que "aunque susceptibles de ser asociadas, nunca [lo serán] de ser reunidas o confundidas". La simple observación, cuando se ha vivido entre los negros -dice d'Eichthal- nos hace sentir que tienen una humanidad distinta de la de los blancos, distinción que viene también demostrada por la ciencia, de acuerdo con las aseveraciones de Pierre Flourens ${ }^{71}$, quien -siempre según d'Eichthal- encontró entre los negros y los indios americanos una capa de piel particular, además de la dermis y la epidermis, responsable de la pigmentación de la piel y de la que carecen los blancos. Las circunstancias exteriores no habrían podido crear es diferenciación física si ambas razas hubieran tenido un antepasado común, sugiriendo quizá, aunque no lo expresan claramente, un origen poligenésico de los seres humanos. La conclusión a la que sí llegan los dos amigos es que las diferencias raciales indican claramente que, al igual que sucede con las diferencias entre sexos, estas dos razas forman una pareja, en la que la raza blanca es el macho y la negra es la hembra, y que la Humanidad reproduce así la ley de dualidad de los sexos a la que obedecen todos los seres orgánicos. Aceptar que la raza negra es la madre no resulta fácil, puesto que los blancos están habituados a considerar a Dios como blanco y al diablo como negro. Pero

\begin{abstract}
"una vez que he visto con claridad cuantos desórdenes y sufrimientos resultan para nuestra sociedad del desarrollo excesivo de la potencia intelectual, he comprendido todo el valor de las virtudes de los negros, su calma, su inocencia, su bondad, la frescura y la delicadeza de su inteligencia, y qué nuevo bienestar debe encontrar nuestro mundo en el contacto con ella. La raza negra es el mundo salvaje de Rousseau, pero despojado de la barbarie, y no sustituyendo sino asociándose al mundo civilizado"72.
\end{abstract}

Cuando una raza nueva llega por primera vez a tener protagonismo en los destinos de la familia humana, sus virtudes y sus cualidades, diferentes de las de la raza que ha dominado hasta ese momento, necesitan tiempo para cultivarse y desarrollarse. Resulta difícil reconocer en las hordas bárbaras que invadieron el Imperio romano a los futuros ciudadanos de París, de Berlín o de Londres. De la misma forma, la raza negra, a excepción de la que ha recibido ya el islamismo, está todavía en "estado bruto", y ni su belleza, ni su moralidad, ni su inteligencia han sido debidamente cultivadas y perfeccionadas, y su educación en las colonias no ha sido la más adecuada a su carácter. La inteligencia del negro, pronta, viva y graciosa, se ahoga en el aparato de formas metafísicas en las que aprisionamos nuestra ciencia y nuestro pensamiento. Su cuerpo, el color

\footnotetext{
${ }^{71}$ Pierre Flourens (1794-1867), médico y biólogo, especialista en estudios neurológicos.

${ }^{72}$ D'Eichthal y Urbain, Lettres, op. cit., p. 16.
} 
de su piel, exigen vestimentas amplias, desembarazadas, de colores vivos y afilados. Hermosos en sus trajes orientales, parecen ridículos embutidos en los trajes europeos, y lo mismo sucede con sus cualidades morales, que se pierden al verse obligados a seguir las nuestras ${ }^{73}$.

Todas estas consideraciones sobre las razas reflejan la posición de los sansimonianos sobre la expansión colonial y, a la vez, las aportaciones de un discípulo diferente como era Urbain. Atención al "otro", acercamiento a través del conocimiento de su manera de ser, pero con el acento puesto en una incorporación lenta y progresiva a la cultura y a los valores comunes, es decir a los europeos. Mezcla de ciencia -según los postulados de la época- y filosofía antropológica, en esa visión de la dualidad padre/madre, muy del gusto de Enfantin, hay una autocrítica de la rigidez metafísica occidental, y confianza en un futuro diferente, mejor y abierto al mundo entero. Pero, al mismo tiempo, hay una reivindicación del Islam -a cuyas virtudes están dedicadas las últimas cartas que componen la obra- como religión "puente" entre la cultura africana y la cristiana. Esta es la tesis de Urbain, a la que se consagró con convicción y entusiasmo. Nacido de africana y europeo, y convertido al Islam, su mestizaje biológico y cultural personificaba ese puente, esa Humanidad emergente, esa raza nueva capaz de comprender todas las culturas. Y Argelia, entre el Mediterráneo y el desierto que separaba y enlazaba el Islam con el África negra, y colonizada por los franceses, era a su vez la tierra donde se operaría el milagro del contacto, la asociación y quizá la comprensión mutua de las tres culturas.

En 1848, tras la caída de la Monarquía de Julio, la nueva república declara que Argelia no es una colonia sino parte integral de Francia. Los nuevos diputados representantes del territorio en la Asamblea eran en su mayoría sansimonianos, y Luís Napoleón, elegido Presidente en diciembre de ese año, reconoció el derecho de las comunidades indígenas a su tierra, a su fe y a su lengua. Fue el triunfo de los seguidores de Saint-Simon en general y de Ismayl Urbain en particular. Un nuevo comienzo.

\footnotetext{
${ }^{73}$ Ibid., pp. 8-19.
} 


\section{Referencias bibliográficas:}

Abi-Mershed, Osama W. Apostles of Modernity. Saint-Simonians and Civilizing Mission in Argelia, Stanford, Stanford University Press. 2010.

Adamovsky, Ezequiel, Diderot en Rusia, Rusia en Diderot, "Studia Historica", $22(2000)$.

Álvarez, Francisco, Mill, la etología que nunca se escribió [en Roberto R. Armayo, Javier Muguerza, Antonio Valdecantos, comps.: El individuo y la historia. Antinomias de la herencia moderna, Barcelona, Paidós, 1995], pp. 79-97.

Assimacopoulou, Fotini, Arthur de Gobineau commenté par Alexis de Tocqueville, "The Tocqueville Revue/La Révue Tocqueville", Vol. XXII, 2 (2001).

Baude, Jean Jacques (1792-1862), L'Algérie, Bruxelles et Leipzig, Meline, Cans et Compagnie, 1841, 2 vols.

Beasley, Edward, The Victorian Reinvention of Race, New Racism and the Problem of Grouping in the Human Sciences, New York, Routledge, 2010.

Béguin, Christian, Tocqueville et l'Algérie, "The Tocqueville Review/La Revue Tocqueville", 2 (2009)

Bodichon, Eugène, Considération sur l'Algérie, Paris, Comptoir Central de la Libraire, 1845.

Burke, Edmund, Speech on Opening the Articles of Impeachment, 15 de febrero 1788, [en F. O'Gorman, Edmund Burke. His Political Philosophy, London. Unwin University Books, 1973].

Description de l'Égypte ou Recueil des abservations et des recherches qui ont été faites en Égypte pendant l'expédition de l'Armée française publié par les ordres de sa Majesté l'Empereur Napoléon le Grand, Paris, Imprimerie Impériale, 1809-1822, 9 vols.

Desjobert, Amédée, La question d'Alger, Politique, Colonization, Commerce, Paris, Capelet, 1837. L'Algerie en 1846, Paris, Guillaumin, 1846. L'Algérie en 1838, Paris, Dufart, 1838. L'Algérie en 1844, Paris, Guillaumin, 1844.

Dureau de la Malle, Adolphe, Recherches sur l'histoire de la régence d'Alger et sur la colonisation de l'Afrique sous la domination romaine, Paris, 1837.

Eichthal, Gustave d' y Urbain, Ismayl, Lettres sur la race noire et la race blanche, Paris, Chez Paulin éditeur, 1839.

Emerit, Marcel, Les saint-simoniens en Algérie, Paris, Les Belles Lettres, 1941. Enfantin, Prosper, Colonisation de l'Algérie, Paris, Bertrand, 1843. 
Exploration scientifique de l'Algérie pendant les années 1840, 1841, 1842, publiée par ordre du gouvernement et avec le concours d'une commission académique, Paris : Impr. royale, 1844-1867, 39 vols.

Ferguson, Niall, Civilization: The West and the Rest, London, Penguin Books, Allen Lane, 2011.

Fisquet, Honoré, Histoire de l'Algérie depuis les temps anciens jusqu'à nos jours : publié d'après les écrits et les documents les plus officiels, Paris, Baudouin, 1842.

Genty de Bussy, Pierre, De l'etablissement des français dans la Regence d'Alger, et des moyens d'en assurer la prosperité, s.1., 1835.

Guizot, François, Cours d'Histoire moderne. Histoire générale de la civilisation en Europe, Bruxelles, Sociéte Belge de Librairie, 1839.

Jaume, Lucien, Tocqueville. Les sources aristocratiques de la liberté. Paris, Fayard, 2008.

Lapène, Edouard, Les Kabaïles comparés aux Numides et aux Vandales, Paris, Anselin et Gaultier-Laguionie, s.f.

Lawlor, Mary, Alexis de Tocqueville in the Chamber of Deputies. His Views on Foreign and Colonial Policy, Washington D.C., The Catholic University of America Press, 1959.

Lorcin, Patricia M.E., Kabyles, arabes, français: identités coloniales. Presses de l'Université de Limoges, 2005.

Mélonio, Françoise, Le choc des civilisations: Chassériau et Tocqueville en Algérie [en Chassériau (1819-1856). Un autre romantisme. Actes du colloque organisé para le Musée du Louvre le 16 mars 2002, Paris, La Documentation Française-Musée du Louvre, 2002].

Mill, John Stuart, Three Essays on Religion [en J. Robson, ed.: Collected Works, vol. X, Essays on Ethics, Religion and Society, University of Toronto Press, Routledge \& Kegan Paul, 1969].

Sobre la libertad, traducción española de Pablo de Azcárate. Madrid, Alianza Editorial, 1981.

Pellissier de Reynaud, Edmond, Les Annales Algériens, Paris, Anselin et Gaultier -Laguionie, 1836-1854, 3 vols.

Pilbeam, Pamela M., The Colonization of Algeria: The role of saint-simonians, http//www.h-france.net/rude/rudevolvi/PilbeamVo16.pdf, consultado el 2 de febrero de 2016.

Pitts, Jennifer, Empire and Democracy: Tocqueville and the Algeria Question, "The Journal of Political Philosophy", vol. 8, 3 (2000), pp. 295-318.

A Turn to Empire. The rise of Imperial Liberalism in Britain and France, Princeton University Press, 2005.

Plassart, Anna, Un 'Impérialiste Libéral': Jean-Baptiste Say on Colonies and the Extra-European World, "French Political Studies", 32, 2 (2009). 
Richter, Melvin, Tocqueville on Algeria, "The Review of Politics", vol. 25, 3, Sonderegger, Arno, Anglophone discourses on Race in the 19th century: British and African Perspectives, "Stichproben. Wiener Zeitschrift für kritische Afrikastudien", 16 (2009), pp. 45-85.

Stokes, Eric, The English Utilitarians and India. Oxford, Clarendon Press, 1959.

Stuurman, Sierp, François Bernier and the Invention of Racial Classification, "History Workshop Journal", Autumn (2000), pp. 1-21.

Todorov, Tzvetan, Présentation de "De la colonie en Algerie", Paris, Éditions Complexe, 1988.

Tocqueville, Alexis de, Oeuvres Complètes, volumen III, tomo 1, Écrits et discours politiques, editado por André Jardin, Paris, Gallimard, 1962.

Oeuvres Complètes, volúmen V, tomo 1, Voyages en Angleterre, Irlande, Suisse et Algérie, editado por J.P. Mayer et André Jardin, Paris, Gallimard, 1958.

Welch, Cheryl B., Out of Africa: Tocqueville's Imperial Voyages, "Review of Middle East Studies", vol. 45, 1 (2011). 
